\title{
PEMANFAATAN LIMBAH JEANS UNTUK BAHAN BARANG FUNGSIONAL YANG DAPAT DIGUNAKAN SEHARI - HARI
}

\author{
Magdalena Viola Cundawan', Shania Hwang Handoko² \\ ${ }^{1}$ Program Studi Desain Interior, Universitas Kristen Petra \\ violacun@gmail.com \\ ${ }^{2}$ Program Studi Desain Interior, Universitas Kristen Petra \\ Shaniahwang30@gmail.com
}

\begin{abstract}
This scientific journals aims to show the benefits of jeans waste that can be used for materials that can be used for everyday use. This scientific journal is based on previous research by making alternative product designs and prototypes ranging from branding to goods that are ready to be sold and marketed. The product developed is called $U$-jeans and consists of several types of designs and functions that are all made from used jeans. This research helps researchers find solutions to reduce jeans waste by product design that attracts consumers' attention. The subjects in the previous research were teenagers and the subjects of this scientific journal were students and the general public. The data collection technique was carried out by survey and observation while the data analysis technique was carried out using the service learning method with three stages namely pre-production, production and post-production. The results of the research and scientific journal writing are that researchers gain knowledge and experience that can be disseminated so that they can form a community in the processing of used jeans waste not only by making into items that will be used privately but into goods that have functions and aesthetics to be marketed.
\end{abstract}

Keywords: jeans wastes, denim textile, jeans, recycle.

\section{PENDAHULUAN}

Di Indonesia masyarakat masih kurang dalam menanggapi isu lingkungan. Banyaknya pakaian tak terpakai yang dibuang sembarangan memang bisa menambah permasalahan limbah tektil. Permasalahan ini dipicu karena perkembangan industri tekstil yang ternyata menimbulkan dampak negatif karena dapat mencemari lingkungan. Setiap hasil produksi yang baru meningkat, hal ini juga akan diikuti dengan pakaian teksil yang dibuang karena sudah usang, robek, maupun tergeser dengan yang baru. Sampah dari pakaian tekstil inilah yang kemudian dibuang dan mencemari lingkungan sekitar. Oleh karena itu, diperlukan adanya suatu inovasi sebagai usaha untuk mengurangi limbah tekstil maupun untuk mengolah limbah tekstil itu sendiri agar dapat mengurangi isu lingkungan yang ada di masyarakat.

Usaha yang dapat dilakukan untuk mengurangi isu lingkungan yang ada di masyarakat dapat dilakukan dengan cara daur ulang sampah. Daur ulang yang dimaksut adalah inisiasi penggunaaan kain bekas khususnya berbahan denim (jeans) untuk didaur ulang menjadi suatu produk yang fungsional dan memiliki nilai lebih sehingga jeans bekas dan sudah tak terpakai dapat diolah ulang kembali. Dalam pengolahan menjadi produk baru yang fungsional digunakan metode pembelajaran yaitu metode Service Learning sehingga tidak hanya mengatasi permasala-han lingkungan namun juga mengatasi permasalahan sosial yang ada di masyarakat.

Metode Service Learning dapat membantu mahasiswa untuk memiliki kemampuan kritis terutama terhadap berbagai situasi dan kondisi sosial yang ditemukan dan hadapi dalam masyarakat yang dialami oleh kelompok mitra yang dituju. Mahasiswa melakukan pelayanan terhadap kelompok mitra agar dapat mengerti situasi dan kondisi real dalam masyarakat untuk meningkatkan rasa empat dalam diri. Mahasiswa akan termotivasi untuk melatih diri melalui menghasilkan sebuah produk inovasi daur ulang yang dikembangkan serta dapat menjadi pembelajaran bagi mitra.

\section{A. Rumusan Masalah}

- Bagaimana desain yang diberikan untuk menanggulangi masalah banyaknya sampah kain bekas?

- Bagaimana cara untuk mengurangi sampah berupa jeans menjadi sesuatu yang berguna bagi kehidupan sehari-hari? 


\section{B. Tujuan Penelitian}

- Untuk memberi solusi guna menanggulangi masalah banyaknya sampah kain bekas

- Untuk memanfaatkan jeans bekas sebagai benda yang berguna bagi kehidupan sehari-hari.

\section{Manfaat Penelitian}

Bagi masyarakat, untuk mengetahui bahwa denim bekaspun dapat dimanfaatkan kembali sebagai benda yang membantu pekerjaan kita dan berguna bagi kehidupan sehari-hari, dapat didesain sedemikian rupa dari daya guna dan daya tariknya.

Bagi mahasiswa, dengan adanya benda yang penulis desain dari denim bekas ini dapat membuat mahasiswa menjadi terinspirasi untuk mengembangkan karya ini sehingga daya guna dapat lebih bervariasi dengan desain yang lebih menarik lagi.

\section{Penelitian yang Pernah Dilakukan}

Penelitian yang pernah dilakukan yaitu pembuatan alternatif desain, pembuatan prototype dari desain yang telah disetujui oleh pembimbing, evaluasi produk dari segi guna dan daya tahan, branding produk daur ulang denim yang sudah didesain sedemikian rupa sehingga cocok untuk digunakan untuk membantu aktivitas manusia.

\section{KAJIAN LITERATUR}

\section{A. Limbah Textil}

Limbah tekstil mengandung bahan-bahan yang berbahaya bila dibuang ke lingkungan, terutama daerah perairan. Sebagian besar bahan yang terdapat dalam limbah tekstil adalah zat warna, terutama zat warna sintetik. Zat warna sintetik merupakan molekul dengan sistem elektron terdelokalisasi dan mengandung dua gugus yaitu kromofor dan auksokrom. Kromofor berfungsi sebagai penerima elektron, sedangkan auksokrom sebagai pemberi elektron yang mengatur kelarutan dan warna. Saat ini, terdapat bermacam-macam jenis zat warna sintetik yang penggunaannya disesuaikan dengan jenis serat yang akan dicelup, ketahanan warna yang dikehendaki, faktor-faktor teknis dan ekonomis lainnya. Pada proses pewarnaan, zat warna yang biasa digunakan pada umumnya tidak akan masuk seluruhnya kedalam bahan tekstil, sehingga efluen yang dihasilkan masih mengandung residu zat warna. Hal inilah yang menyebabkan efluen tekstil menjadi berwarna-warni dan mudah dikenali pencemarannya apabila dibuang langsung keperairan umum. Masalah lingkungan yang utama dalam industri tekstil adalah limbah dari proses pencelupan. Zat warna, logam berat dan konsentrasi garam yang tinggi merupakan polutan air (Dewi, 2009).

\section{B. Jeans}

Jeans merupakan salah satu pakaian yang menjadi favorit bagi anak muda yang biasa digunakan untuk kegiatan sehari-hari. Jeans semakin berkembang baik dari segi model, desain, dan bahan celana jeans. Jeans berasal dari Genoa, Italia, jeans diproduksi untuk keperluan angkatan laut, sebagai celana yang dapat dipakai basah ataupun kering. Nama jeans sendiri didapat dari bahasa Perancis yang menyebut celana warna biru asal Genoa ini sebagai Bleu De Gnes. Jeans adalah sebuah produk celana yang menggunakan bahan denim, denim itu sendiri merupakan kain yang terbuat dari bahan alam yaitu kapas atau disebut katun (cotton), dibuat dari serat kapas yang dibuat kasar dan ditenun secara diagonal menggunakan tambahan bahan tertentu. Pada tahun 1800 an di Genoa, dibuatlah pembuatan celana dari bahan kain denim. Ternyata celana dari denim ini banyak yang menyukai tidak hanya masyarakat Genoa melainkan juga warga Perancis. Dari sinilah penyebutan istilah jeans berasal. Jadi kain denim adalah bahan untuk membuat celana yang dinamai Jeans atau di Indonesia disebut Jins. Karakter awal celana Jeans yang dibuat pertama kalinya belum senyaman masa sekarang. Yang diutamakan tentu kekuatannya dalam menunjang pekerjaan lapangan yang keras dan kasar. Banyak pekerja tambang Amerika memakai celana jeans sehari-harinya.

\section{Daur ulang}

Daur ulang adalah proses untuk menjadikan suatu bahan bekas menjadi bahan baru dengan tujuan mencegah adanya sampah yang sebenarnya dapat menjadi sesuatu yang berguna, mengurangi penggunaan bahan baku yang baru, mengurangi penggunaan energi, mengu-rangi polusi, kerusakan lahan, dan emisi gas rumah kaca jika dibandingkan dengan proses pembuatan barang baru.

Banyak manfaat yang diperoleh dari pendaur ulangan bahan bekas yang ada di sekitar kita, seperti plastik bekas, kertas bekas, kayu bekas, dan lainlain. Daur ulang dapat meningkatkan kreativitas, mengurangi pencemaran dan sebagainya. Berikut akan kami jelaskan beberapa manfaat yang ada dalam usaha pengelolaan sampah daur ulang. Manfaat yang diperoleh antara lain:

1) Membuka lapangan kerja. Manfaat yang paling menonjol adalah masyarakat dapat membuka lapangan kerja. Bekerja di sektor formal saat ini 
sempit kesempatannya. Melamar pekerjaan membutuhkan syarat tertentu. Lowo-ngan pekerjaan sedikit, sehingga sulit mencari pekerjaan. Usaha daur ulang ini dapat membuka lapangan kerja bagi masyarakat di sektor informal. Dengan bertambahnya lapangan pekerjaan bagi masyarakat, tingkat pengangguran dapat dikurangi.

2) Meningkatkan pendapatan masyarakat. Berkreasi dari bahan bekas menjadi kerajinan-kerajinan tangan lalu didistri-busikan kepada masyarakat dapat meningkatkan pendapatan. Apalagi bahan baku daur ulang tidak membutuhkan modal yang besar. Dalam ekonomi, usaha seperti ini dapat menekan biaya operasional dan retribusi. Sehingga pemerintah daerah lebih ringan dalam pengeluaran pengelolaan sampah. Barang daur ulang mempunyai nilai ekonomi yang menghasilkan pendapatan. Sehingga masyarakat dapat berdaya secara ekonominya. Pemberda-yaan ekonomi rakyat yang dimaksud disini adalah adanya pendapatan atau penghasilan yang bisa diperoleh dari hasil penjualan barang olahan dari bahan bekas menjadi barang yang mempunyai nilai ekonomi. Dengan memperoleh penghasilan tersebut masyarakat dapat meningkatkan kesejahteraan dan dapat memenuhi kebutuhan hidupnya.

3) Mengurangi pencemaran lingkungan. Sampah yang dibakar dan limbah pabrik dapat menyebabkan pencemaran lingkungan. Mendaur ulang sampahsampah dan memanfaatkan limbah, dengan menjadikannya barang kerajinan dan barang-barang kreasi lainnya, pencemaran lingkungan dapat dikurangi.

4) Menghemat sumber daya alam. Berkreasi dari bahan bekas dapat menghemat sumber daya alam sebagai bahan baku kebutuhan hidup manusia. Contohnya, dengan mendaur ulang kertas kita dapat mengurangi laju pengurangan jumlah pohon.

5) Mencegah penyakit. Sampah yang menumpuk dapat menyebabkan penyakit. Dengan mendaur ulang sampah-sampah, tumpukan sampah akan berkurang. Tingkat kebersihan pun akan meningkat jika pengelolaan sampah berjalan dengan baik.

6) Menambah kreativitas dan keterampilan. Dengan berkreasi dari bahan bekas, kita akan lebih kreatif dan terampil. Kita dapat menemukan ide-ide baru yang kreatif dan inovatif dalam berkreasi.
Langkah-Langkah Daur Ulang Atau Pemanfaatan Ulang:

- Pemisahan. Limbah yang akan didaur ulang atau dimanfaatkan ulang dipisah-kan dengan limbah yang harus dibuang ke tempat pembuangan.

- Penyimpanan. Limbah yang sudah dipisahkan tadi disimpan dalam kotak yang tertutup. Usahakan setiap kotak yang tertutup hanya berisi satu jenis material limbah tertentu, misalnya kertas bekas atau botol bekas.

- Pengiriman atau penjualan. Barang-barang yang sudah terkumpul dapat dijual ke pabrik yang membutuhkan material bekas sebagai bahan baku atau dapat dijual atau diberikan ke pemulung.

Macam-macam limbah yang dapat di daur ulang. Berikut adalah beberapa jenis limbah atau material yang dapat dimanfaatkan melalui daur ulang:

1) Kertas. Semua jenis kertas dapat di daur ulang, seperti kertas koran dan kardus.

2) Gelas. Botol kecap, botol sirup, dan gelas / piring pecah dapat digunakan untuk membuat botol, gelas, atau piring yang baru.

3) Aluminium. Kaleng bekas makanan dan minuman dapat dimanfaatkan kembali sebagai kaleng pengemas.

4) Baja. Baja sisa kontruksi bangunan akan berguna sebagai bahan baku pembuatan baja baru.

5) Plastik. Limbah plastik dapat dilarutkan dan diproses lagi menjadi bahan pembungkus (pengepakan) untuk berbagai keperluan. Misalnya, dijadikan tas, botol minyak pelumas, botol minuman, dan botol sampo.

\section{METODE PENELITIAN}

\section{A. Sampel}

Produk U-JEANS ditargetkan untuk seluruh kalangan namun lebih khusus untuk dipasarkan ke remaja dan dewasa muda yang tinggal di area perkotaan. Kebutuhan di dalam rumah untuk memuat banyak benda seperti alat tulis, buku, makeup, baju dan barang-barang lainnya memicu U-JEANS untuk menghasilkan sebuah produk multifungsi agar menarik minat pembeli khususnya kalangan remaja dan dewasa muda.

\section{B. Batasan-Batasan}

- Physical Assets: Bahan yang dipakai yaitu dari jeans bekas yang didapatkan dari hasil sumbangan berbagai pihak (keluarga, teman, kolega) 
- Intellectual: Fokus terhadap perma-salahan lingkungan yaitu limbah kain khususnya sisa kain jeans yang tidak terpakai, ide muncul untuk memanfaatkan sisa dan di daur ulang dengan melakukan research serta brainstorming.

- Human: Bekerja sama dengan UMKM penjahit di area Pacar Keling Surabaya ( Revo Tailor) untuk menghasilkan produk dari jeans bekas.

- Financial: Mendapatkan / dana dari pribadi serta subsidi dari universitas.

\section{Teknik Pengumpulan Data}

- Metode Survei

Sebelum produksi hal yang dilakukan pertama adalah observasi mitra yang akan diajak bekerja sama dan observasi permasalahan yang ada di lingkungan yang akan diangkat dan dijadikan pertimbangan untuk menjadi bahan produksi.

- Observasi Permasalahan

Permaslahan yang kami angkat adalah bahan sisa dari tailor atau penjahit yang tidak terpakai khusus nya kain jeans yang sering di permark dan menghasilkan banyak sisa. Kami menilai bahwa amat sangat sayangkan jika jeans bekas hanya terbuang sia-sia, padahal jeans bekas yang sudah tidak dapat digunakan sebagai pakaian, masih bisa dimanfaatkan menjadi barang lain yang memiliki nilai jual.

- Observasi Mitra

Karena bahan utama yang digunakan sebagian besar berasal dari penjahit maka kami mengajak mitra yang sebagian besar pekerjaannya permark jeans yaitu Penjahit Revo Tailor. Dan produk UJEANS ini terdapat varian keranjang maka kami mengajak mitra Tukang Kayu Putra Tunggal untuk membuat kerangka keranjang yang terbuat dari kayu.

\section{Teknik Analisis Data}

\section{- Metode Service Learning}

Service Learning adalah melatih mahasiswa agar memiliki pengetahuan tentang situasi nyata dalam masyarakat dan kemampuan untuk mengatasinya, serta untuk membentuk karakter terutama agar mereka memiliki kesadaran berbela rasa atau peduli terhadap kaum yang lemah dan tersisihkan Metode ini dianggap sebagai jembatan yang menghubungkan pembelajaran dan pelayanan melalui sebuah proses refleksi. Selain dipandang dapat membantu mengembangkan dimensi spiritual dan sosial mahasiswa, juga jembatani kesenjangan antara teori atau ilmu yang dipelajari di kelas dan praktek nyata secara pribadi dalam kehidupan mereka di masyarakat. Service Learning membantu mahasiswa untuk memiliki kemampuan kritis terutama terhadap berbagai situasi dan kondisi sosial yang mereka temukan dan hadapi dalam masyarakat yang dialami oleh komunitas mitra dimana mereka ditempatkan. Mahasiswa akan dimotivasi untuk melatih diri mereka bagaimana mencapai kematangan intelektual dengan menghadapi berbagai persoalan nyata.

\section{E. Langkah Penelitian}

- Tahap Pra Produksi

Brandstorming idea dan konsep untuk desain produk yang akan dibuat untuk menjawab permasalahan limbah denim bekas, membuat sebanyak mungkin alternatif, memilih dari alternatif yang sudah dibuat dan melakukan evaluasi desain serta mendapatkan persetujuan pembimbing agar pembuatan produk dapat dilakukan, lalu pembuatan prototype.

- Tahap Produksi

Setelah melakukan tahap - tahap tersebut kami mengontrol dan memastikan produksi dan kualitas dari produk U-JEANS. Setelah selesai di produksi kami mulai proses pengemasan produk, setiap produk diberi kemasan sesuai dengan ukuran dan yang terakhir adalah tahap pemasaran, yaitu dengan memasarkan produk kami melalui media sosial dan platform jual beli online, selain itu kami bekerja sama dengan Project $X$ Market untuk menyediakan venue dan memarkan produk UJEANS untuk mempromosikan produk kami agar semaki dikenal oleh masyarakat

- Tahap Pasca Produksi

Tahapan akhir yang dilakukan adalah kegiatan pelaporan yang berada pada tahap pasca produksi. Tahap pelaporan berisikan laporan data kegiatan mulai dari tahap pasca produksi dan tahap produksi dengan durasi waktu tertentu. Tahap pelaporan ditujukan untuk mengetahui rangkaian kegiatan usaha dan keuntungan yang didapat, sehingga diperoleh data yang akurat sebagai bahan evaluasi. 


\section{HASIL DAN PEMBAHASAN}

\section{A. Business Model Canvas}

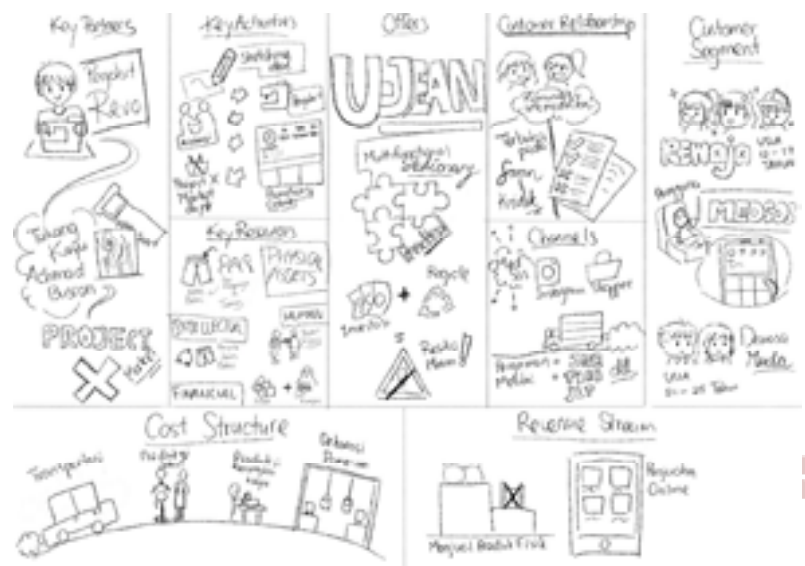

Diagram BMC (Sumber: Gunawan, 2019)

\section{B. Key Partners}

- Penjahit Revo Tailor

Sumber daya manusia yang akan menyulap kainkain jeans bekas menjadi produk stationary UJEAN.

- Tukang Kayu Putra Tunggal

Sumber daya manusia yang membuat kerangka dari produk keranjang jeans U-JEAN.

\section{Key Activities}

- Production: Mendesain berbagai alternatif sketsa untuk produk yang akan di pasarkan kemudian desain terpilih diserahkan pada penjahit dan setelah itu hasil produksi siap dipasarkan.

- Problem Solving: Sebelum menentu-kan produk yang akan dipasarkan, asistensi dan konsultasi produk dibutuhkan untuk menerima masukan agar dapat menghasilkan produk yang baik.

\section{Offers}

- Menawarkan produk stationery (tempat penyimpanan barang) yang multifungsi, usefull dan trendy untuk dapat digunakan dengan mudah serta praktis.

- Investment dengan resiko yang tidak besar dikarenakan memanfaatkan bahan baku yang di daur ulang bukan menggunakan bahan baru.

\section{E. Customer Relationships}

- Terbuka dengan saran dan kritik dari konsumen untuk dapat mengem-bangkan produk menjadi lebih baik di masa depan.
- Menerima permintaan-permintaan khusus dari konsumen untuk modifikasi produk sesuai dengan yang konsumen inginkan.

\section{F. Channels}

- Jalur Penjualan produk UJEANS melalui media sosial (Instagram \& LINE@), platform online shop (Shopee) dan berkesempatan untuk menjual produk di market atau bazar

- Jalur distribusi produk yaitu menyerahkan bahan baku kepada tenaga kerja, setelah produk siap akan langsung dipasarkan. Jika terjadi transaksi melalui media sosial dan platform online shop maka produk akan dikirimkan melalui kurir - kurir yang tersedia seperti JNE, TIKI, J\&T, Si Cepat dan lain -lain.

\section{G. Pengembangan Produk dan Proses Produksi 1}

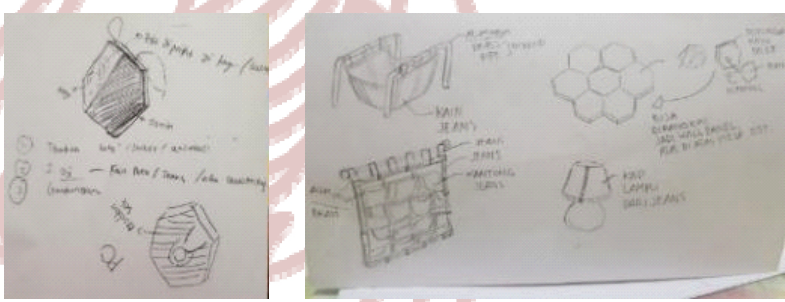

(Sumber: Gunawan, 2019)

Dua gambar sketsa tersebut merupakan sketsa awal penampung ide-ide tentang desain-desain yang sesuai untuk menjawab permasalahan limbah jeans, dan melalui brainstorming ide dan pembuatan alternatif seperti pada sketsa di atas, maka dapat dihasilkan 4 macam produk yaitu karpet oktagonal, dekorasi dinding oktagonal, tempat koran dan buku, dan sarung bantal seperti yang terlihat pada gambar di bawah ini.
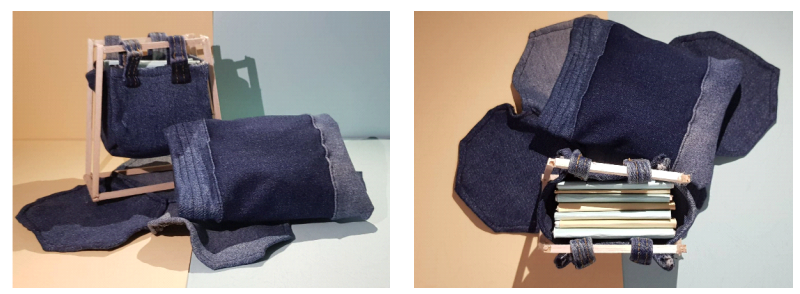

(Sumber: Gunawan, 2019) 


\section{H. Prototype Dari Setiap Produk Dengan Skala:} Skalatif

1. Karpet Hexagon dan Aksesoris Dinding Hexagon
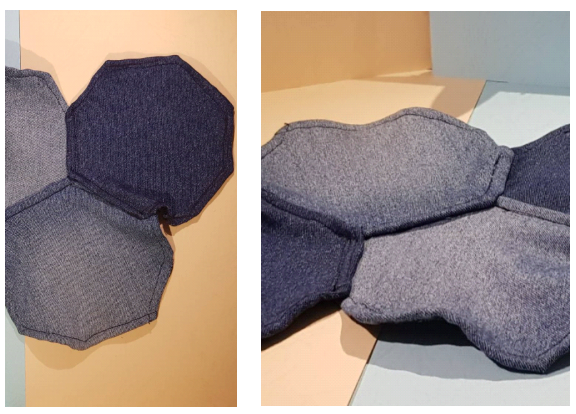

(Sumber: Gunawan, 2019)

\section{Sarung Bantal}
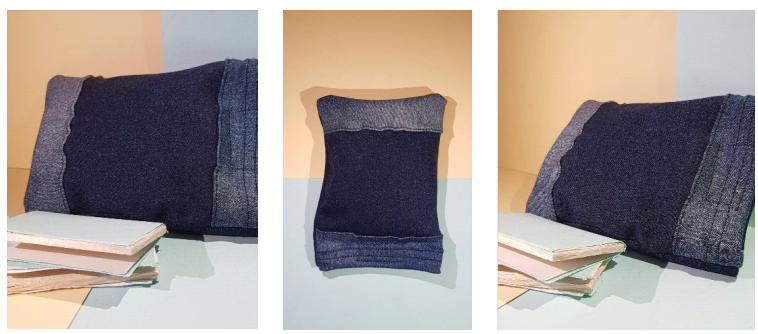

(Sumber: Gunawan, 2019)

Sarung bantal sebagai aksesoris ruangan yang dapat dilettakan di sofa untuk mempercantik ruangan. Nantinya motif dari sarung bantal ini akan dibuat berbeda-beda sehingga lebih menarik dan variatif.

Desain dengan bentuk ini akan menjadi 2 macam produk yang pertama adalah karpet ruangan dengan ukuran kurang lebih $1.50 \mathrm{~m} \times 70 \mathrm{~cm}$. Sedangkan produk kedua sebagai aksesoris dinding yang akan ditambahkan multipleks dibelakangnya serta pocket untuk storage barang berdiameter $12 \mathrm{~cm}$. Memiliki bentuk oktagonal karena oktagonal memiliki nilai estetika tersendiri saat digabungkan dengan bidang oktagonal lainnya sehing lebih mudah untuk dipadukan sesuai dengan bentuk yang kita inginkan.

\section{Tempat Koran dan Buku}
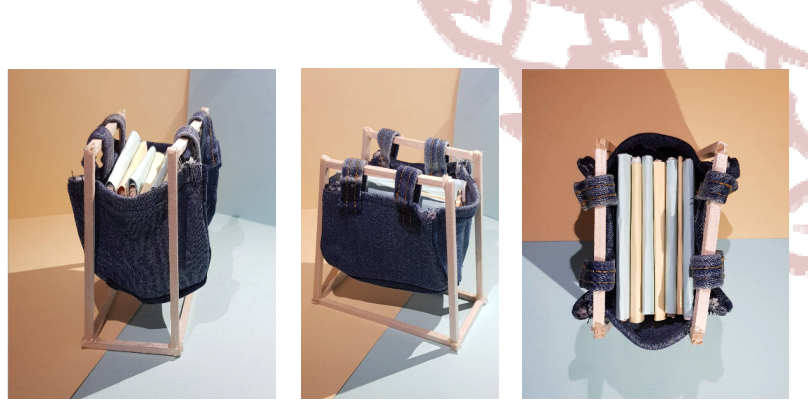

(Sumber: Gunawan, 2019)

Produk ini kami desain sebagai tempat untuk storage koran dan buku-buku sehingga koran dan buku tidak berantakan melainkan dapat terorganisir dalam satu tempat. Dengan melakukan survey diberbagai tempat dan surfing browsing lewat internet didapatkan bentuk modern minimalis ini di mana desain storage koran dan buku ini cocok untuk segala konsep dan diletakkan di mana saja, simple and clean.

\section{Calon SDM}
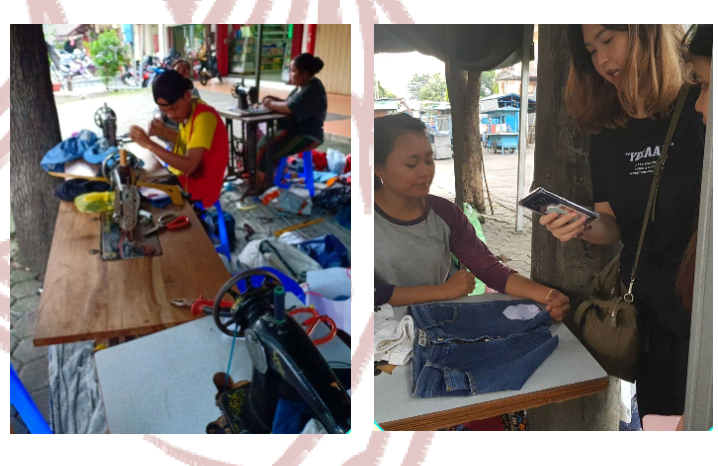

(Sumber: Gunawan, 2019)

Foto di atas merupakan foto praktikan dan calon SDM yang sedang melakukan wawancara dan pertemuan untuk persetujuan kerja sama pembuatan U-JEANS ini. Calon SDM ini adalah tempat permak baju, namun lebih khusus dalam menangani jeans. Terletak di daerah Mulyosari di dekat Bank Danamon.

\section{KESIMPULAN}

Hasil penelitian menunjukan bahwa manfaat dari limbah jeans dapat digunakan untuk bahan-barang yang dapat digunakan sehari-hari. Terdapat banyak produksi limbah textile dalam sehari-hari dan salah satunya adalah limbah jeans dan untuk mengurangi limbah denim usaha yang dapat dilakukan adalah melakukan daur ulang. Daur ulang yang maksud adalah inisiasi penggunaan jeans untuk memproduksi suatu produk yang fungsional dan memiliki nilai. Penelitian dilakukan berdasarkan riset sebelumnya dengan membuat alternatif desain produk dan proto- 
type mulai dari branding hingga barang yang siap dijual dan dipasarkan. Produk yang dikembangkan dinamakan U-JEANS dan terdiri dari beberapa jenis desain dan fungsi yang semuanya berbahan dasar dari jeans bekas.

Penelitian ini membantu dalam menemukan solusi untuk mengurangi limbah jeans dengan desain produk yang menarik perhatian konsumen. Subjek dalam penelitian sebelumnya adalah remaja dan subjek dari jurnal ilmiah ini adalah mahasiswa dan masyarakat umum. Teknik pengumpulan data dilakukan dengan survey dan observasi sedangkan teknik analisa data dilakukan dengan metode service learning dengan tiga tahap yaitu pra produksi, produksi dan pasca produksi. Dalam penelitian ini peneliti dapat menyimpulkan bahwa desain dari sebuah produk sangat penting terutama dari sisi fungsi dan estetika. Selain fungsi dan estetika, desain dan subjek atau konsumen yang ditargetkan harus seirama sehingga konsumen tertarik.

\section{UCAPAN TERIMA KASIH}

Penulis mengucapkan terima kasih kepada Tuhan yang Maha Esa atas segala berkat yang telah diberikan kepada penulis sehingga penulis dapat menyelesaikan karya tulis berupa jurnal ini dengan baik. Tidak lupa juga, penulis mengucapkan terima kasih kepada:

1. Dr. Yusita Kusumarini, S.Sn., M.Ds., selaku dosen pembimbing yang telah dengan sabar membimbing sampai terbentuknya U-Jeans.
2. Dr. Laksmi Kusuma Wardani, S.Sn., M.Ds., selaku dosen mata kuliah seminar sekaligus dosen pembiming yang meluangkan waktu, tenaga, dan pikiran dalam membimbing penulis menye-lesaikan jurnal ini.

\section{DAFTAR PUSTAKA}

Alamendah (2011). Pengertian dan Proses Daur Ulang. Retrieved from https:// alamendah.org/2011/ 01/22/pengertian-dan-proses-daur-ulang/

Ibeng, Parta (2019). Pengertian Daur Ulang, Tujuan, Manfaat, Proses, dan Macamnya. Retrieved from https:// pendidikan.co.id/pengertiandaur-ulang-tujuan-manfaat-proses-danmacamnyal

Ibeng, Parta (2019). Pengertian Limbah MenurutAhli, Jenis, Karakteristik, dan Dampaknya. Retrieved from https:// pendidikan.co.id/ pengertian-limbah-menurut-ahli-jeniskarakteristik-dan-dampaknya/

Niswita, RH (2016). Pengelolaan Limbah Cair Domestik Dengan Proses Elektrokoagulasi. Retrieved from http:// eprints.polsri.ac.id/952/3/ BAB\%20II.pdf

Wolipop (2012). Denim \& Jeans, Serupa Tapi Tak Sama. Retrieved from https:// wolipop.detik.com/fashion-news/d-2095247/ denim-jeans-serupa-tapi-tak-sama 